\title{
Study on the Change in Social Value of Mass Sports in China Jun $\mathrm{Hu}$

\author{
Baoshan University; Baoshan Yunnan 678000 China
}

\author{
Keywords: mass sports; Social value; Change; Research.
}

\begin{abstract}
China, the mass sports cause of our country has been in a relatively good state of development. With China's comprehensive national strength increased, the development of mass sports of our country's social value presents a relatively good trend. And its function is also gradually improving, sports powers on the road to a positive role in China's development is becoming more and more obvious. For China's mass sports, its social value is also different. Based on this, this article plans to our country economic system, economic system transformation and the socialist market economy gradually perfect the three stages of development of mass sports value has carried on the related research and discussion.
\end{abstract}

\section{Introduction}

As an important part of China's socialist modernization, sports cause plays a very active role in displaying comprehensive national strength. China has always been a great sports power in the world, compared with sports power there is still a big gap. Although with the continuous improvement of China's comprehensive national strength, China's sports cause has been greatly developed. But from our country present stage I current situation of the development of undertakings of physical culture and sports, competitive sports and mass sports, because is restricted by many factors, its development level is still stays at a relatively low status, especially mass sports. As for the development of mass sports in China, it has different social values and social functions in different social periods. Only do a good job in the value of its corresponding research and analyzes its regularity and can promote the vigorous development of mass sports in our country, to realize our country sports power construction level of ascension.

\section{The Change of Social Value of Mass Sports in China}

As a social phenomenon with worldwide characteristics, sports, both competitive sports and mass sports, are closely related to the social environment during its development. As for the social environment, the development and change of sports are often influenced by many aspects, such as politics and economy. Accordingly, in the process of mass sports development, also tend to be affected by the decision to force, that is, the social value of mass sports in our country also with the change of social environment with dramatic changes.

\subsection{Hard Development of Mass Sports in the Planned Economy}

The so-called planned economy system refers to the period from the beginning of the founding of new China to the period before the third plenary session of the eleventh central committee of the communist party of China (1951-1977). In this stage, the mass sports under the planned economy system is in the primary stage of the establishment of mass sports. This phase of mass sports and the planned economy system maintain the same, belongs to the government-led mass sports management mechanism, belongs to a compulsory behavior. At the same time, it is restricted by economic conditions, and China's mass sports has been in a difficult state of development [2].

At this stage, China held three national games and one national minority traditional sports congress. In 1952, Mao Zedong inscription "sports development, improve the people's physical fitness," for the sports development of new China laid the important ideological basis, it also marks the mass sports of our country has entered the early stages of development. At this stage, the implementation of the "labor defense system" and the "instructions on strengthening the sports work of people's names" by the Chinese government provided the corresponding basis and standards for the development of mass 
sports. Generally speaking, mass sports in this period is a kind of political need, whose main value is to meet the specific requirements of the internal and external struggle of the country, and to meet the requirements of national development on this basis. Therefore, in this period, the mass sports function of our country mainly stays on the original function of sports but does not show other functions and values.

\subsection{The Preliminary Development of Mass Sports Under the Stage of Economic Restructuring}

The period of economic transformation refers to 1978-2008, namely 30 years of reform and opening up. In 1978, the third plenary session of the eleventh central committee of the communist party of China pointed out that "the focus of the party's work should be shifted to socialist modernization". The victory of the third plenary session of the meeting and marked the socialist construction of our country into a new historical stage, during this period, constantly improve and stabilize the political system in our country and achieve the change from planned economy to market economy. After 30 years of development, the ability of our country's economy has been rapid ascension, and in terms of competitive sports, our country also has made the world, obtained the considerable development of sports industry in China. In this context, the country's mass sports management system also implements the dominated by the government to the government management and the transition of the management system of the combination of social management, make the development of mass sports in our country has entered the preliminary stage in the development of [3].

At this stage, our country has introduced policies and standards, for our country's mass sports development provides a strong system guarantee, and with the baptism of the international sporting events, as well as the rapid development of economy, our country competitive sports enterprise obtained the rapid development of worldwide has made a lot of outstanding achievements. However, as far as China's mass sports are concerned, it is still in the primary stage of development despite the corresponding development. In this period, China's development is mainly centered on economic development, so the social value of mass sports in China is also changing, and the function of mass sports is also increasing [4].

\subsection{The Rapid Development of Mass Sports at the Establishment Stage of the Socialist Market Economy System}

The socialist market economy system establishment stage means since 2009, since 2008, when the background the Olympics after the victory, our country will be the annual August 8 as the national fitness, a "government organization, the crowd full participation in mass sports pattern formation. During this period, the state council issued by the national construction regulations, the national fitness program (2011-2015) and the national basic public service system "twelfth five-year" plan "and other relevant regulations, to include the national fitness in the national basic public service system, marks the development of mass sports in our country has not only stay at the policy level, but has entered the phase of a solution to the problem [5], in this way, to realize the rapid development of mass sports in our country has a very positive meaning.

During this period, under the unified role of government management and social management, China's mass sports have developed rapidly, and has begun to transform to "social sports". In addition, more and more social capital has been invested in sports and physical fitness, and the mass sports in China has also been developed rapidly. But because of the economic structure, management system and operational mechanism of various kinds of factors, such as our country's sports industrial structure still need to constantly improve, therefore, at present the development of mass sports, the distance to the actual needs of the national fitness, there are still gaps. In this period, the social value increment function of mass sports in China has been fully reflected, and its social value has also been greatly improved.

\section{Overview of Social Functions of Mass Sports}

\subsection{It is Conducive to Promoting Social Welfare and Improving People's Livelihood}

Sports as a kind of has a larger value activity, its development history is very long, and sports rights is one of basic human rights, with the continuous development of society, all countries 
formulate relevant laws to protect people's sports right. With the changing of social environment, people often used to acknowledge and accept the social values, and in the process of government work, the hope that through the mass sports, to improve some bad social value in the society. For national development, to do a good job of mass sports, to save health care and health care financing is a very positive significance, therefore, many countries have formulated the corresponding policy or regulation, to encourage the people to widely participate in the mass sports activities. Many countries, for example, often through the media to spread the positive role of mass sports, make more and more people are involved in the actual mass sports, is not only beneficial to people's health, and to promote social welfare, improve the quality of life play a very active role in [6], for improving our country's comprehensive national strength has a very profound influence.

\subsection{It is Conducive to Promoting Economic Growth and Improving the Quality of Education}

As a fast-developing industry in recent years, sports economy plays a very positive role in promoting the overall improvement of China's economic level. With the continuous development of mass sports in our country, the investment direction and investment intensity of our government and society have changed dramatically. for example, in the process of mass sports development, strengthen the construction of sports organization and management and related sports venues, is not only beneficial to increase people's sports participation enthusiasm, will also be born in a large degree promote people for sports consumption ability, and with the rapid development of mass sports in our country, our country's sports economy in our country in the process of the development of the national economy share also will be more and more big.

Not only that, in the process of mass sports development, with the improvement of its level of development, it not only can promote the growth of the economy, and in improving the level of physical education, plays a very active role. With the coming of information era, people's production and life more convenient, the importance of health for people is becoming more and more high, thus, to schools, clubs, associations and professional groups in our country put forward the higher request, to promote the teaching quality of ascension has very positive meaning.

\subsection{It is Conducive to the Formation of Personality and the Formation of Correct Moral Values}

With the improving of the level of information level in our country at present stage, although it is possible in a large extent, enrich the people access to information, but also to the social development has brought many negative effects, among them, the most prominent is the personality flaws, for example, at this stage we call WeChat fans, curtilage, Weibo, etc., this kind of person due to lack of exercise for a long time, its ability to communicate with people and values, there are various defects. For mass sports, it can not only strengthen people for cognitive cooperation, sharing, and abide by the rules, but also in a large extent, improve the participants' moral concept and social skills, in improving the personality defect of modern people have a very positive role.

\section{Analysis on the Value-Added Strategy of Mass Sports}

\subsection{Solve the Contradiction Between Policy and Implementation}

Factors restricting our mass sports function value has a lot of, one of the most main reason is that in the process of mass sports development, still there are many contradictions, make the function of mass sports in our country it is difficult to achieve value-added. Only by analyzing these major contradictions and proposing corresponding solutions can we truly realize the improvement of the functional value of mass sports in China. The first is the contradiction at the government level. The main contradiction is the contradiction between policy and implementation, which is embodied in the following two aspects.

First, there is the contradiction between the weak material basis of mass sports and the high standard of mass sports [7]. The main way to solve this contradiction is: in the development of mass sports, the relevant government decision makers should discard formalism and sense of prestige projects, according to the actual requirements of the development of mass sports, sports venues and facilities construction really implement, and on this basis, provide good foundation for the development of mass sports. In addition, it is necessary to increase the training of mass sports 
instructors, constantly improve their social status, and finally realize the improvement of social value of mass sports.

Secondly, there is a certain contradiction between the government's leading sports departments or social forces in organizing sports activities and the actual results. Only by constantly to perfect the mass sports management system, and on the basis of constantly improve the level of mass sports management systematic and organized, can fundamentally to implement the actual effect of mass sports in China, finally realizes the value enhancement.

\subsection{Solve the Contradiction Between People's Cognition and Practice}

In addition to the above contradictions, there are also major contradictions in the development of mass sports. Its main manifestation is the contradiction between mass cognition and practice [8]. As a result, the contradiction between cognition and practice, for the masses to solve this contradiction, countries should continuously intensify publicity, help people to set up "lifetime sports" consciousness, let people really involved in the actual mass sports, and on this basis, enhance the social value of mass sports in our country.

\section{Conclusion}

To sum up, it is not hard to find that the development of mass sports in China is still unbalanced and at a low level. With the continuous improvement of comprehensive national strength, the mass sports in our country have also been changing constantly, and its social function has been greatly strengthened. The arrival of the era of "comprehensive fitness" is not only conducive to the improvement of the construction level of China's sports power, but also plays a very positive role in the great rejuvenation of the Chinese nation.

\section{References}

[1]. Wang Zhiming. Research on the development trend of mass sports lifestyle [J]. Journal of Liaoning university of technology (social science edition), 2008,20(02):139-142.

[2]. Chen Tao, Yi Gaoming. Research on the implementation mechanism and performance improvement strategy of China's mass sports policy [J]. Journal of three gorges university (humanities and social sciences edition), 2014,40(02):112-114.

[3]. Huang He. Research on the development of rural mass sports [J]. Journal of Changchun normal university, 2013,37(02):92-94+126.

[4]. li Yangxing. Research summary of mass sports in the context of national fitness era [J]. Western leather, 2008,40(02):39.

[5]. Liu Guoyong. Some thoughts on the development of mass sports in the new era [J]. Sports science, 2008,38(01):4-8+17.

[6]. Liu Fang. Research on mass sports system and policy experience in developed countries [J]. Journal of Chifeng university (natural science edition),2017,33(22):39-40.

[7]. LAN Jian, tan Gongxia, Zhang Yunbing. Research on the correlation between the prosperity of mass sports and social benefits [J]. Sports technology,2017,38(04):88-89.

[8]. Wang Fuqiu, Wang Songtao. Social value change of mass sports in China [J]. Sports culture guide,2015(02):40-43. 